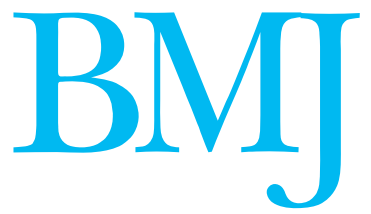

\title{
The human tissue bill
}

\section{Criminal sanctions linked to opaque legislation threaten research}

$\mathrm{T}$ The new human tissue bill is making its way towards the statute book for England, Wales, and Northern Ireland. Although a necessary response to the organ retention scandal involving the Royal Liverpool Children's NHS Trust, this bill goes far wider than tissues derived from post mortems. ${ }^{1}$ It applies to any material that contains human cellseven urine and sputum. Using such material for research or for training not "incidental to the diagnostic process" will be a criminal offence unless "appropriate" consent has been obtained. Possible penalties include three years in jail. Punitive criminal sanctions coupled with opaque legislation threaten ethical and essential research as well as routine NHS activities. Incidental and appropriate have yet to be defined by a new human tissue authority, which will have powers of licensing and inspection. But the government has repeatedly said that consent must be explicit, ${ }^{2}$ even in relation to medical training using residual blood samples that would otherwise be incinerated. ${ }^{3}$

We know that the public does not regard surgically resected tissue in the same way as postmortem tissue. ${ }^{4}$ Putting aside the question of whether residual urine samples really deserve legal protection comparable to that accorded to a dead baby's heart, the question remains-can it work, and does it command both professional and public confidence? Does this bill focus so much on individual rights that the benefits to society of research and training are ignored?

Laboratory staff cannot ask for consent after the patient has gone home, and it is usually impossible to know which samples will be of value for training or research at the time of sampling. Therefore, if staff training and hence care for patients are not to suffer the wishes of all patients must be recorded and made available to laboratory staff. This is the government's intention.

One suggestion is that tick boxes should be placed on all pathology request forms. In a pilot in High Wycombe 68\% of forms had neither "consent" nor "refuse" ticked. A clause on the standard surgical consent form has been suggested, although such forms are not used for blood sampling. A trial in Leeds showed that the laboratory could trace only $48 \%$ of the forms, and $40 \%$ of those were not complete. Many forms contained contradictory statements, indicating that surgeons had not actually explained the issues to patients. ${ }^{5}$ Consent without information is invalid ${ }^{6}$; how can invalid consent be appropriate? Therefore, one possible for the good of society, will be incinerated not because the patients wish it but because of bureaucracy.

Politicians have underestimated the size of this problem. In Leicester, for every autopsy performed 1215 samples from living patients are examined. Across the United Kingdom, about 150 million samples are examined each year. All fall under this bill. Imagine that a paltry one minute of staff time is taken for each sample-to ask the questions, listen to the answers, record the answers, and transcribe them into a database. One hundred and fifty million minutes per year equates to 1339 full time jobs. That is the entire staff of a medium sized NHS hospital. Add another minute to provide patients with some minimal information, and another hospital is fully occupied. Another minute to answer a question, and another hospital is unavailable. The initial government statement of the financial implications of the bill ignored this cost. This is not the only problem.

Despite assurances that codes of practice issued by the human tissue authority will rectify the situation little detail exists in the bill of how licensing for the storage of tissue for scheduled purposes (for example, research) will work in practice. Furthermore individuals rather than premises will be licensed; a problem in terms of individual liability and the current arrangements for the custodianship of tissue banks, which presently lies with host institutions. Finally, the new offence of "DNA theft" is yet another example of punitive, ill fitting legislation. So sweeping is this clause-it prohibits the intention to carry out DNA analysis without qualifying consent-that it threatens accidentally to criminalise bona fide public health research.

As it stands the proposed legislation is impractical and punitive. So what are the solutions? A powerful case exists for the use of ethically approved research by using anonymised tissue samples without consent. ${ }^{7}$ Strangely, the bill and its accompanying notes never once mention ethics committees. This would provide an immediate solution. A further strategy would be to seek up front consent at the time of booking into hospital or registration with a general practitioner, where patients could be provided with information sheets in the waiting rooms and their consent for using their tissue for research and education could be sought. This strategy would be flexible and patient friendly. It would provide guidance for later if the patient is incapacitated. It could be extended to other issues of patients' choice-it might even reduce the shortage of organ donors. It could be sold politically as a new way to increase choice and 
empower patients. It was proposed in $2001,{ }^{8}$ yet the government has so far ignored the idea.

The human tissue authority should also be subject to greater parliamentary accountability, and the licensing requirements need to be more tightly defined to avoid pointless bureaucracy. The poor wording of the bill also needs to be addressed; seeking to create legislative flexibility is not an excuse for ambiguous and complex drafting. If the human tissue bill is not amended then it will ultimately fail the public; perceived improvements in the regulation of human tissue will come at the price of less medical research, education, and training.

Peter Furness professor

Department of Pathology, Leicester General Hospital, Leicester LE5 4PW (peter.furness@leicester.ac.uk)

Richard Sullivan head of clinical programmes

Research Management and Planning Directorate, Cancer Research UK, London WC2A 3PX

(Richard.Sullivan@cancer.org.uk)
Competing interests: $\mathrm{PF}$ is involved in training health service staff in ways that use human tissue in microscopic slides and with photomicrographs. He is also involved in research that uses tissue (from biopsies).

1 Royal Liverpool Children's Inquiry. The report of the Royal Liverpool children's inquiry (the "Richards report"), 2001. www.rlcinquiry.org.uk/

2 Donaldson L. Proposals for new legislation on human organs and tissue. London: Department of Health, 2003. www.doh.govuk/tissue/ lon: Department of Health, 2003.

3 Winterton R. Verbal response. House of Commons official report (Hansard). 2004 Feb 3, col 188.

4 Medical Research Council. Public perceptions of the collection of human biological samples. London: MRC, 2001. www.wellcome.ac.uk/en/images/ biolcoll_3182.pdf (accessed 25 Feb 2004).

5 Agarwal M, Sugden J, Quirke P. Introduction of consent for surgically removed tissue-report of two audits.J Pathol 2003;201(suppl):49A.

6 Department of Health. Good practice in consent implementation guide: consent to examination or treatment. London: DoH, 2001. www.dh.gov.uk/ PolicyAndGuidance/HealthAndSocialCareTopics/Tissue/ TissueGeneralInformation/TissueGeneralArticle/fs/ en?CONTENT ID = 4002298\&chk=s2N3bw (accessed 25 Feb 2004).

7 Medical Research Council. Human tissue and biological samples for use in research. London: MRC, 2001. (Medical Research Council Ethics Series.)

research. London: MRC, procedures for handling "surplus" and archival material from human biological samples. London: Royal College of Pathologists, 2001. www.rcpath.org/ index.php?PageID = 208 (accessed 25 Feb 2004).

\section{Treating malaria in Africa}

\section{Sulfadoxine-pyrimethamine may still have a future despite reports of resistance}

$\mathrm{F}$ or many years the treatment of malaria in Africa has relied on chloroquine, sulfadoxine combined with pyrimethamine, and quinine, with the latter being used mainly to treat severe cases. Quinine remains efficacious, but chloroquine and sulfadoxinepyrimethamine are failing, and this is leading to an increase in mortality from malaria especially in East Africa. ${ }^{12}$

Although resistance to chloroquine was first detected on the east coast of Africa in 1977, the drug has provided effective treatment for malaria for much of Africa for over 20 years. ${ }^{3}{ }^{4}$ Unfortunately this is unlikely to be the case for sulfadoxine-pyrimethamine, the combination adopted by several African countries as the first line treatment for malaria when chloroquine has failed. Systematic surveillance for resistance to malaria drugs and the results of trials of new drugs or drug combinations that could be used to replace chloroquine or sulfadoxine-pyrimethamine are showing a worryingly high level of resistance to sulfadoxinepyrimethamine across eastern and southern parts of Africa. ${ }^{56}$ Resistance to sulfadoxine-pyrimethamine is particularly severe in north east Tanzania, where clinical failure rates of up to $50 \%$ have been described, ${ }^{7}$ but high levels of resistance have been recorded also in parts of Burundi, Kenya, Rwanda, and Uganda. ${ }^{8}$ Levels of resistance to sulfadoxine-pyrimethamine are generally lower in West Africa, but clinical failures are not infrequent, and parasites carrying mutations associated with resistance to sulfadoxine-pyrimethamine are distributed widely across West Africa. Genetic studies show that resistance to sulfadoxine-pyrimethamine may have arisen in southern and eastern Africa on only a few occasions, so these resistant strains have spread extensively and rapidly. ${ }^{9}$ Sulfadoxine-pyrimethamine seems to have little future as a first line antimalarial in Africa. However, the results of a recent study by Plowe et al (p 545) in Malawi raise the possibility that this conclusion may be too pessimistic. ${ }^{10}$

Malawi changed from chloroquine to sulfadoxinepyrimethamine as first line treatment for malaria in 1993, the first country in Africa to do so. Plowe et al report clinical and parasitological responses of children with uncomplicated clinical episodes of malaria to treatment with sulfadoxine-pyrimethamine five to nine years later (in 1998 and 2002). In 1998, $86 \%$ of children showed an adequate clinical response 14 days after treatment; four years later the response rate was still $83 \%$. Twenty eight days after treatment clinical response rates were $73 \%$ and $61 \%$, respectively, a modest but statistically significant fall over time. Parasitological cure rates 14 days after treatment were 73\% in 1998 and $60 \%$ in 2002 but were much worse 28 days after treatment $-38 \%$ and $27 \%$, respectively. Some of the apparent 28 day failures may have been reinfections, but even if this was the case it indicates a high level of resistance to sulfadoxine-pyrimethamine, as a single dose of sulfadoxine-pyrimethamine gives up to four weeks of prophylaxis against parasites that are sensitive to the combination.

How robust are these unexpected findings of a relatively stable level of resistance to sulfadoxinepyrimethamine? The strengths of this study are that it was carried out by the same investigators at the same site using the same methods of analysis over the four year study period and that the numbers of children studied each year (82-425) were large enough to have detected a decline in efficacy. Dropout rates were quite high but were similar in each survey. A progressive fall in the clinical efficacy of sulfadoxine-pyrimethamine would have been detected had it occurred.

The results of this study from Malawi indicate that, in contrast to the situation in other countries such as Thailand and South Africa, a moderate level of resistance to
Papers p 545 BMJ 2004;328:534-5 